\title{
AEROTHERMODYNAMICS OF EXPERT BALLISTIC VEHICLE AT HYPERSONIC SPEEDS
}

\author{
A. M. Kharitonov ${ }^{1}$, N.P. Adamov ${ }^{1}$, V.F. Chirkashenko ${ }^{1}$, \\ I. I. Mazhul ${ }^{1}$, S. I. Shpak ${ }^{1}$, A. N. Shiplyuk ${ }^{1}$, \\ L. G. Vasenyov ${ }^{1}$, V. I. Zvegintsev ${ }^{1}$, and J. M. Muylaert ${ }^{2}$ \\ ${ }^{1}$ Khristianovich Institute of Theoretical and Applied Mechanics \\ Siberian Branch of the Russian Academy of Sciences \\ Novosibirsk, Russia \\ ${ }^{2}$ Von Karman Institute \\ Brussel, Belgium
}

The European EXPErimental Re-entry Test bed (EXPERT) vehicle is intended for studying various basic phenomena, such as the boundary-layer transition on blunted bodies, real gas effects during shock wave/boundary layer interaction, and effect of surface catalycity. Another task is to develop methods for recalculating the results of windtunnel experiments to flight conditions. The EXPERT program implies large-scale preflight research, in particular, various calculations with the use of advanced numerical methods, experimental studies of the models in various wind tunnels, and comparative analysis of data obtained for possible extrapolation of data to in-flight conditions. The experimental studies are performed in various aerodynamic centers of Europe and Russia under contracts with ESA-ESTEC. In particular, extensive experiments are performed at the Von Karman Institute for Fluid Dynamics (VKI, Belgium) and also at the DLR aerospace center in Germany. At ITAM SB RAS, the experimental studies of the EXPERT model characteristic were performed under ISTC Projects 2109, 3151, and 3550, in the T-313 supersonic wind tunnel and AT-303 hypersonic wind tunnel.

\section{INTRODUCTION}

The EXPERT ballistic reentry capsule was proposed by the European Space Agency (ESA) [1, 2]. The vehicle, designed for obtaining in-flight experimental data on aerothermodynamics at high supersonic velocities, is supposed to be launched by the Volna launcher with subsequent ballistic descent [3].

This is an Open Access article distributed under the terms of the Creative Commons Attribution-Noncommercial License 3.0, which permits unrestricted use, distribution, and reproduction in any noncommercial medium, provided the original work is properly cited. 
Since 2002 till now, experimental studies of the EXPERT reentry capsule have been performed in ITAM SB RAS wind tunnels in frame of ISTC projects Nos. 2109, 3151, and currently ongoing project 3550 .

The EXPERT vehicle will be used

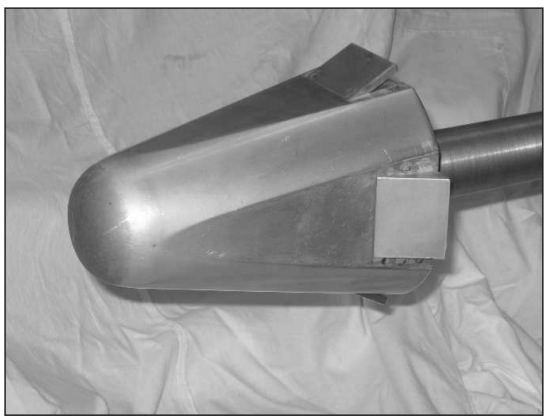

Figure 1 General view of the EXPERT 4.2 model for in-flight research of various critical aerothermodynamic phenomena, such as the boundary-layer transition on blunt bodies, real gas effects during shock wave/boundary layer interaction, effect of surface catalyticity, etc. The effective solution of the problem posed implies comprehensive preflight research, including numerical studies by advanced numerical methods and experimental studies of models in ground-based facilities for possible extrapolation of wind-tunnel data to flight conditions.

The general view of the EXPERT model manufactured at a scale of 1:8 is shown in Fig. 1. The experiments were performed on the EXPERT 4.2 (initial version) and EXPERT 4.4 models (the last modified version).

Same results of earlier studies in ITAM wind tunnels can be found in [4-8]. The present paper describes new data obtained for the EXPERT model, namely:

- results of experimental studies of the total aerodynamic characteristics of the model EXPERT 4.2 in the T-313 blowdown wind tunnel at a Mach number $\mathrm{M}=4$ and in the adiabatic-compression AT-303 wind tunnel with a contoured nozzle at $\mathrm{M}=8,10$, and 14 ;

- results of studying the boundary-layer transition on the model EXPERT 4.2 at $\mathrm{M}=4$ in the $\mathrm{T}-313$ wind tunnel;

- experimental data on the pressure distribution over the surface at $M=8$ (EXPERT 4.4) and $\mathrm{M}=10$ (EXPERT 4.2) in the AT-303 wind tunnel and some comparison of experimental and calculated data by the Euler and Navier-Stokes equations; and

- results of heat flux measurements to the model EXPERT 4.4 surface at $\mathrm{M}=14$.

\section{EXPERIMENTAL CONDITIONS}

The experiments were performed in two hypersonic wind tunnels at Khristianovich's Institute of Theoretical and Applied Mechanics SB RAS, T-313 and AT-303. 


\section{$2.1 \quad$ T-313 Blowdown Wind Tunnel}

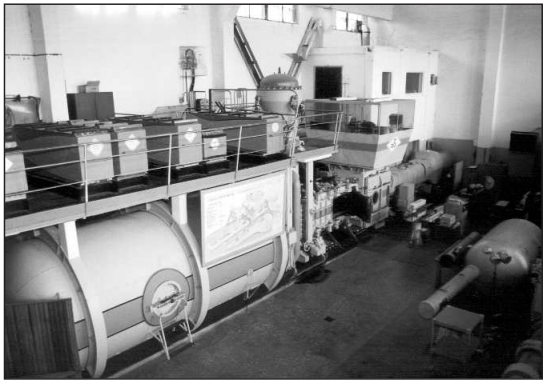

Figure 2 Blowdown supersonic wind tunnel

Experimental data in the T-313 blowdown wind tunnel (Fig. 2) with a 600 $\times 600 \mathrm{~mm}$ test section were obtained at a free-stream Mach number $M$ $=4.04$, unit Reynolds number Re $=50.4 \cdot 10^{6} 1 / \mathrm{m}$, total pressure $q$ $=7.5 \cdot 10^{4} \mathrm{~Pa}$, and angles of attack $\alpha=-2^{\circ}-16^{\circ}$.

The aerodynamic forces were measured with an AB-313 mechanical balance, which is a standard measuring tool for T-313 tests. The measurement ranges for the drag and lift forces and pitching moment were $101.8 \mathrm{~kg}$, $61.7 \mathrm{~kg}$, and $16.4 \mathrm{~kg} \cdot \mathrm{m}$, respectively. The instrumental error is estimated as $0.015 \%-0.045 \%, 0.25 \%-0.8 \%$, and $0.15 \%-0.5 \%$ of the indicated ranges.

Apart from the total aerodynamic characteristics, Schlieren pictures of the flow around the model were taken with an IAB-451 shadowgraph and oil-film pictures of model surface streamlines.

\subsection{AT-303 Adiabatic Compression Wind Tunnel}

The force measurement program in AT-303 (Fig. 3) included measurements of aerodynamic characteristics of the EXPERT model at a nominal Mach number

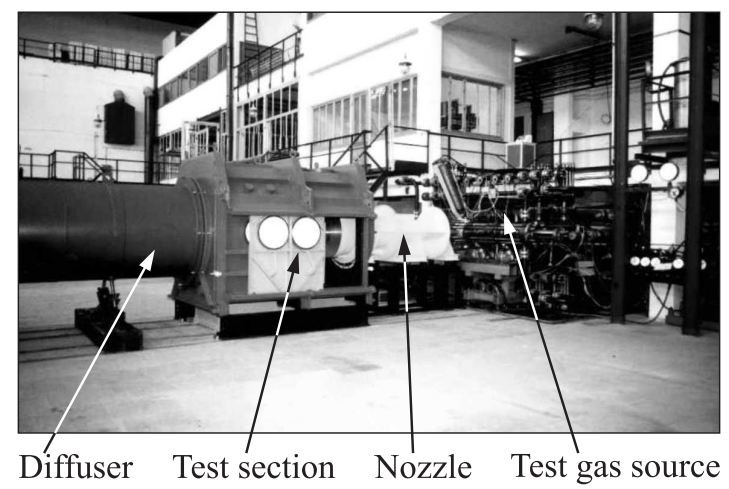

Figure 3 AT-303 wind tunnel with adiabatic compression 
$\mathrm{M}=8,10$, and 14 and unit Reynolds number $\mathrm{Re}=3 \cdot 10^{7}, 4.1 \cdot 10^{7}$, and $1.55 \cdot 10^{7} 1 / \mathrm{m}$, respectively, which is close to natural in-flight. Values angles of attack were $\alpha=0^{\circ}, 3^{\circ}$, and $6^{\circ}$, and rolling angles of the model with respect to the longitudinal axis $\gamma=0^{\circ}, 45^{\circ}$, and $90^{\circ}$.

The study was carried out in a contoured nozzle with an exit diameter $D_{n}$ $=400 \mathrm{~mm}$. The flow velocity field was preliminary measured with a Pitot rake. According to experimental data, the Mach numbers at the nozzle exit for the indicated Reynolds numbers were $\mathrm{M}=8.35,9.75$, and 13.8 .

The force measurements in AT-303 were performed by a six-component strain-gauge balance. The errors in the measured total aerodynamic forces have been discussed in $[5,7]$. Note that to check the reliability of the data obtained, same tests were duplicated. The model nose was located at a distance of $\sim 25 \mathrm{~mm}$ behind the nozzle exit.

\section{TOTAL AERODYNAMIC CHARACTERISTICS}

All values of the aerodynamic force coefficients presented below were normalized to the reference area $F_{\text {ref }}=0.0187 \mathrm{~m}^{2}$; the pitching moment coefficient was additionally normalized to the reference length $L_{\text {ref }}=0.2 \mathrm{~m}$. The pitching moment was determined with respect to the model nose tip. The aerodynamic force coefficients are plotted in the coordinate system fitted to the sting (straingauge balance).

The initial position of the model in the wind tunnels corresponded to the state with the "open" flaps aligned in the vertical symmetry plane of the model; in the present test series, the deflection angle of all the four flaps was $\delta=20^{\circ}$. It should be noted that to provide appropriate rolling angles $\gamma$, the model was turned with respect to the longitudinal axis of the strain-gauge balance whose position remained unchanged in all tests.

\section{$3.1 \quad$ T-313 Wind Tunnel}

In processing the measured data for aerodynamic loads on the EXPERT model and in determining the flow conditions, the routine procedure for the T-313 facility was used.

The aerodynamic coefficients in the sting-fitted coordinate system are shown in Fig. $4 a$ vs. the angle of attack. Two positions of the model are considered: the initial position with a rolling angle $\gamma=0^{\circ}$ and the second position with the model rotated with respect to the longitudinal axis by a rolling angle $\gamma=45^{\circ}$.

It should be noted that a nonzero angle of the model had weak influence on the aerodynamic characteristics throughout the whole examined range of angles 


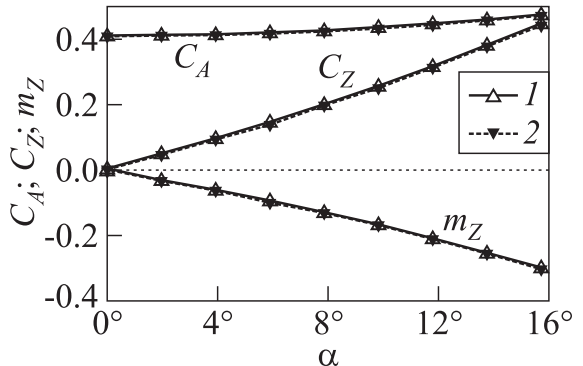

(a)

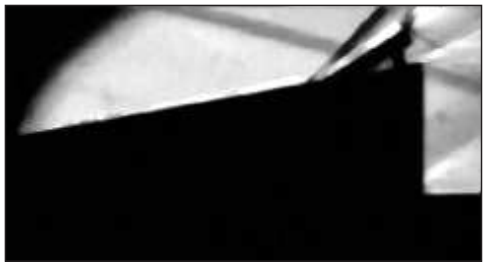

(b)

Figure 4 Aerodynamic characteristics of the EXPERT model at $M=4: 1-\gamma=0^{\circ}$; and $2-\gamma=45^{\circ}(a)$ and Schlieren picture of the flow around the model at $\alpha=0^{\circ}$ and $\gamma=0^{\circ}(b)$

of attack. From the theoretical point of view, it is clear that the characteristics at $\alpha=0^{\circ}$ should be independent of model rotation with respect to the longitudinal axis. That is why a comparison of data obtained at $\alpha=0^{\circ}$ and rolling angles $\gamma=0^{\circ}$ and $45^{\circ}$ allows possible errors induced by flow asymmetry in the experiments to be revealed. For instance, these may be wash-induced errors, errors owing to the angle of the model misaligned on the sting or on the $\alpha$-mechanism of the wind tunnel, etc. An almost perfect

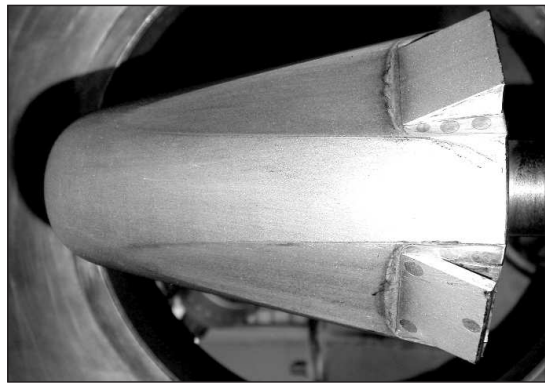

Figure 5 Oil-film visualization performed in T-313 data coincidence for $\gamma=0^{\circ}$ and $45^{\circ}$ obtained at $\alpha=0^{\circ}$ points to the absence of errors of the above-indicated types and to good repeatability of tests in the T-313 wind tunnel.

The longitudinal force coefficient $C_{A}$ somewhat increases with the angle of attack. For $\alpha=0^{\circ}-16^{\circ}$, this coefficient ranges in the interval $C_{A}=0.41-0.47$.

Apart from the total aerodynamic characteristics, some data were obtained concerning the flow structure near the model at the regimes under consideration. For instance, Fig. $4 b$ shows the Schlieren picture of the flow around the model at $\alpha=0^{\circ}$ and $\gamma=0^{\circ}$. The boundary-layer region on the model and the boundary-layer interaction with flap-induced compression shocks are distinctly seen in the images. Based on these data, one can conclude that the boundarylayer separation, if any, occurs within a rather small region, especially at low angles of attack. This conclusion is supported by oil-film visualization of the 
flow over the model surface obtained at $\alpha=0^{\circ}$. An example is given in Fig. 5, which clearly shows convergence lines interpreted as lines of boundary-layer separation.

\section{$3.2 \quad$ AT-303 Wind Tunnel}

The tests in the adiabatic-compression wind tunnel were performed at a nominal free-stream Mach numbers $\mathrm{M}=8,10$, and 14 with the use of a contoured nozzle with an exit diameter $D_{n}=400 \mathrm{~mm}$.

The AT-303 facility is a short-duration wind tunnel; that is why, a critical point here is realization of the test regime with incident flow parameters weakly changing in time. The time evolution of the flow regime at the nozzle exit during the wind-tunnel run is shown in Fig. 6 for $\mathrm{M}=14$ : dynamic pressure $q$ and the unit Reynolds number $\operatorname{Re}_{1}$ vs. time. A rather weak variation of flow parameters over a time interval lasting for $\Delta t \sim 100 \mathrm{~ms}$ is worth noting; these data prove that the working regime necessary for measurements is provided.

The experimental data obtained are plotted in Fig. 7 for aerodynamic coefficients in the balance-fitted coordinate system. It should be noted that the longitudinal force coefficient changes weakly with the angle of attack. Repeated tests show quite satisfactory convergence of the data for all components of the aerodynamic forces. Note that the data for $\mathrm{M}=14$ were obtained in two test series, the data convergence being rather good. At the same time, for the normalforce and pitching moment coefficients at $\mathrm{M}=8$ and 10 , some deviation from zero at the angle of attack $\alpha=0^{\circ}$ is seen.

The effect of the rolling angle provided by model rotation with respect to the longitudinal axis of the balance was studied at all Mach numbers. The data were obtained for rolling angles $\gamma=0^{\circ}, 45^{\circ}$, and $90^{\circ}$ at $\mathrm{M}=14$. Let recall

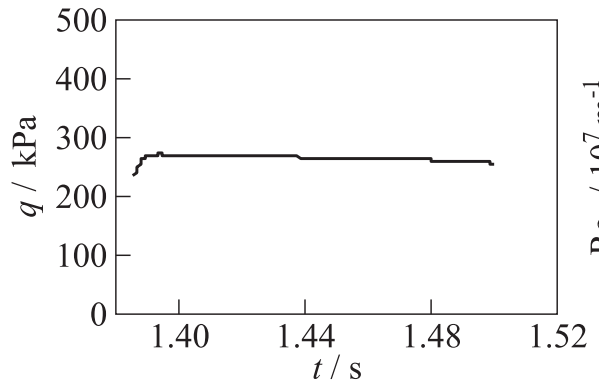

(a)

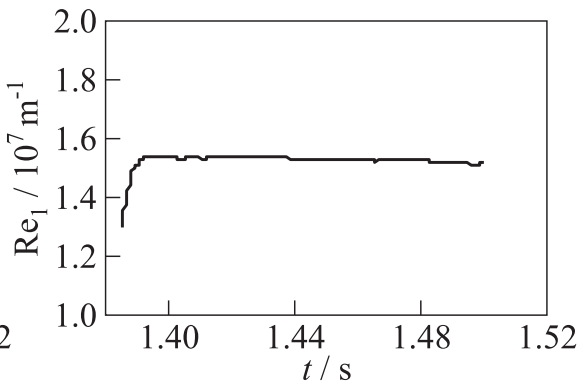

(b)

Figure 6 AT-303 wind tunnel free-stream parameters 


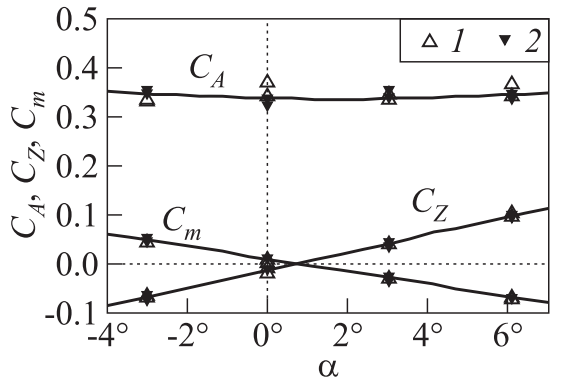

(a)

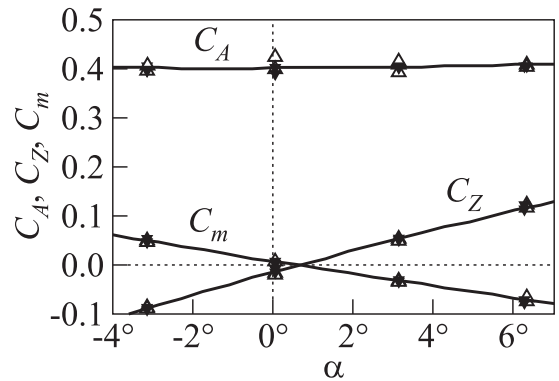

(b)

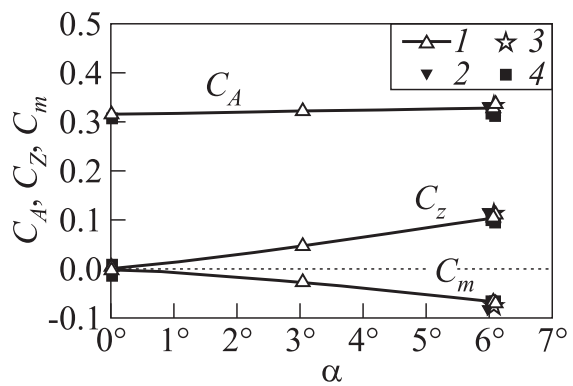

(c)

Figure 7 Aerodynamic characteristics at $\mathrm{M}=8.35\left(\operatorname{Re}_{1} \sim 3 \cdot 10^{7} \mathrm{~m}^{-1}\right)(a) ; \mathrm{M}=9.75$ $\left(\operatorname{Re}_{1} \sim 4.1 \cdot 10^{7} \mathrm{~m}^{-1}\right)(b) ;$ and $\mathrm{M}=13.8\left(\operatorname{Re}_{1} \sim 1.55 \cdot 10^{7} \mathrm{~m}^{-1}\right)(c): 1-\gamma=0^{\circ} ; 2-$ $45^{\circ} ; 3-\gamma=90^{\circ}$; and 4 - preliminary series

that the angles $\gamma=0^{\circ}$ and $90^{\circ}$ refer to the location of the "open" flaps in the vertical plane and horizontal planes of symmetry, respectively. As in $\mathrm{T}-313$ tests at $\mathrm{M}=4$, the aerodynamic coefficients here proved to be independent of the rolling angle of the model.

Figure 8 shows the varying coefficient of the longitudinal force regarding the Mach number to compare the obtained experimental and numerical simulation data [9]. Satisfactory agreement of the data can be noted, excluding $M=10$. This divergence is likely to be caused by the nonuniformity of the velocity field in the

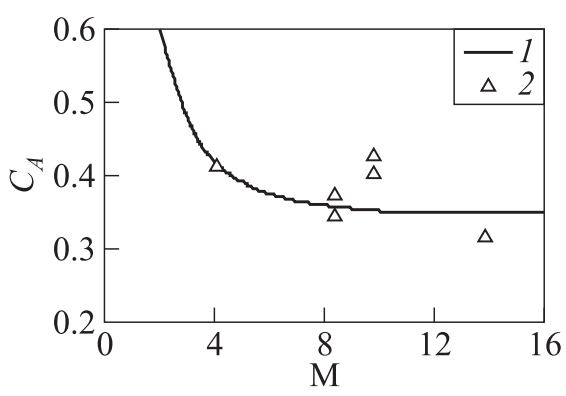

Figure 8 Longitudinal force coefficient: 1 - calculations [9], $\alpha=5^{\circ}$; and 2 - experiments ITAM, $\alpha=0^{\circ}, \gamma=0^{\circ}$ 
flow core, registered by the measurements on the first countered nozzle section. More well-founded reasons of this divergence will be studied in detail.

\section{BOUNDARY LAYER TRANSITION}

The experimental data for the boundary-layer transition on the surface of the EXPERT model were obtained in the T-313 wind tunnel at a free-stream Mach number $\mathrm{M}=4.04$ for an angle of attack $\alpha=0^{\circ}$.

For the purposes pursued in the present study, there was used a method where the boundary-layer transition was measured with the help of Pitot probes located directly on the model surface at a fixed point $x_{0}$ along the longitudinal axis, the free-stream parameters, in particular, the unit Reynolds number $\operatorname{Re}_{1}(1 / \mathrm{m})$, being varied. This method implies that the Pitot probes are expected to register the pressure minimum (maximum) when the free-stream parameters correspond to the beginning (end) of the boundary-layer transition. Thus, analyzing the dependences for the measured values of the dimensionless pressures $p / p_{0}$, it was possible to determine the critical Reynolds numbers at the beginning and end of the boundary-layer transition. Hereinafter, $p_{0}$ is the free-stream total pressure assumed to be equal to the pressure in the wind-tunnel settling, and is the pressure measured by the Pitot probe on the model.

Syringe needles with an outer diameter $d_{0}=0.4 \mathrm{~mm}$ and inner diameter $d_{1}=0.15 \mathrm{~mm}$ were used as Pitot tubes. In the initial position of the model in the wind tunnel, the "open" flaps were aligned in the vertical plane of symmetry. Two Pitot probes were mounted on the model: one in the aforementioned vertical plane of symmetry at a streamwise distance $x_{0}=26.7 \mathrm{~mm}$ from the model tip (referred to as point 1), and the second one in the plane turned by a rolling angle of $45^{\circ}$, at $x_{0}=24.9 \mathrm{~mm}$ (point 2 ). The positions of the Pitot probes and the photograph of the model forebody are shown in Fig. 8. These Pitot probes were mounted on the model surface so that the distance between the probe tip and the place of probe attachment was greater than (15-20) $d_{0}$.

The free-stream unit Reynolds number $\mathrm{Re}_{1}$ was changed in each test by varying the total pressure in the settling chamber in the interval $p_{0} \approx(1.7-13)$ $\times 10^{5} \mathrm{~Pa}$, which covered the range $\mathrm{Re}_{1} \approx(8-64) \cdot 10^{6} 1 / \mathrm{m}$. The total pressures here were measured with the help of TDM2-A pressure sensors, which could measure pressures up to $1.6 \cdot 10^{5} \mathrm{~Pa}$ within $0.5 \%$. The actual pressure level was $(0.1-0.9) \cdot 10^{5} \mathrm{~Pa}$.

Two series of tests were conducted. The first series was performed on the model with natural uncontrolled surface roughness remaining after the force measurements in AT-303 and T-313 wind tunnels as a result of model surface exposure to the flow, especially on the blunt forebody. In the second series, the roughness was appreciably reduced by polishing the model surface. 

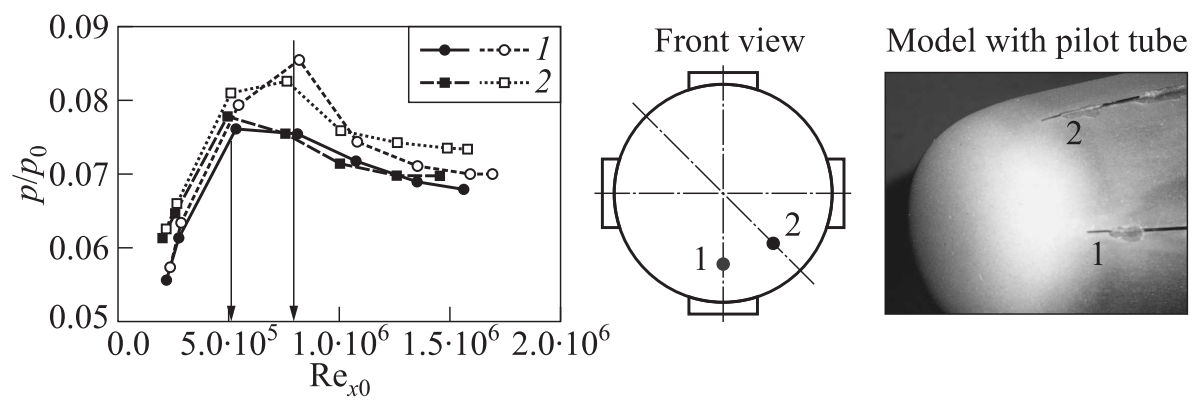

Figure 9 Determination of the boundary-layer: 1 - point $1 ; 2-$ point 2. Black signs refer to initial roughness and empty signs to smooth surface transition

The measured data were used to plot the curves $p / p_{0}$ vs. the Reynolds number $\operatorname{Re}_{x 0}=\operatorname{Re}_{1} x_{0}$ ( $x_{0}$ is the streamwise coordinate of the Pitot probe at point 1 or 2). These curves are shown in Fig. 9 for two test series, with rough and smooth surfaces of the model. Note that both Pitot probes registered close values of $p / p_{0}$, because these probes were located at roughly identical distances from the model tip, in the region of mating of spherical bluntness with the conical part of the model. Only the end of the transition region could be determined in these tests, as there is only the maximum on the curves $p / p_{0}=f\left(\operatorname{Re}_{x 0}\right)$. Identification of the beginning of the boundary-layer transition necessitates reaching lower numbers $\mathrm{Re}_{1}$, which was impossible because of violation of the wind-flow regime at low total pressures $p_{0}<1.5 \cdot 10^{5} \mathrm{~Pa}$. It also follows from the data of Fig. 9 that surface roughness largely affects the magnitude of the critical Reynolds number $R_{e t}$. For instance, $\operatorname{Re}_{\text {et }} \sim 5 \cdot 10^{5}$ was obtained for the rough surface; for the smooth surface, the boundary-layer transition was found to occur further downstream, and the critical Reynolds number increased to $\operatorname{Re}_{\text {et }} \sim 8 \cdot 10^{5}$.

As a whole, it can be concluded that a turbulent boundary layer was formed on the major part of the model surface, including the region of the flaps. This conclusion complies with the oil-film pictures of surface streamlines $(\mathrm{M}=4.05$, $\operatorname{Re}_{1} \approx 50 \cdot 10^{6} 1 / \mathrm{m}$ ), which show only an insignificant separation zone resulting from the boundary-layer interaction with flap-induced shock waves.

The critical Reynolds numbers obtained in these tests allow the probable position of the end of the boundary-layer transition under natural flight conditions to be estimated. For instance, for fight trajectories with a reentry velocity $V=5000 \mathrm{~m} / \mathrm{s}$, the Reynolds number based on the vehicle length is $\operatorname{Re}_{L} \approx 1.5 \cdot 10^{7}$, and the unit Reynolds number is $\operatorname{Re}_{1 \infty} \approx 9.7 \cdot 10^{6} 1 / \mathrm{m}$. Then, the coordinates of the transition end points, calculated as $x_{\mathrm{et}}=\operatorname{Re}_{\mathrm{et}} / \mathrm{Re}_{1 \infty}$, are 0.083 and $0.052 \mathrm{~m}$ for the smooth and rough surfaces, respectively. In other words, the laminar-turbulent transition occurs near the model tip, on the seg- 
ment of the clotoid connecting the spherical bluntness with the conical part of the surface.

\section{PRESSURE DISTRIBUTION OVER THE SURFACE}

The pressure distributions over the surface of the EXPERT model were measured at a Mach number $\mathrm{M}=10$ in a conical nozzle with an exit diameter $D_{n}=400 \mathrm{~mm}$ with the following free-stream parameters: stagnation pressure $P_{0}=9850 \mathrm{kPa}$, stagnation temperature $T_{0}=1024 \mathrm{~K}$, and unit Reynolds number $\operatorname{Re}_{1}=6.8$ $\times 10^{6} 1 / \mathrm{m}$. The angles of attack of the model were $\alpha=0^{\circ}, 3^{\circ}$, and $6^{\circ}$. For the overall pressure distribution pattern on the windward and leeward sides of the model to be obtained, the pressure measurements for each angle of attack were performed in two wind-tunnel runs with the model turned by 180 degrees with respect to the longitudinal axis.

To ensure the possibility of pressure measurements, the EXPERT model was equipped with 20 pressure taps located in the vertical plane of symmetry (Fig. 10). Five of these taps were located on the flap with $\delta=20^{\circ}$. The diameter of all pressure holes was $1 \mathrm{~mm}$.

The pressure measurements were performed with TDM2-A absolute pressure sensors installed inside the model as close to the model surface as possible. Signals were recorded by SCP 3200 high-precision multichannel measuring system. The registration lasted for $3.3 \mathrm{~s}$, which included the duration of the hypersonic

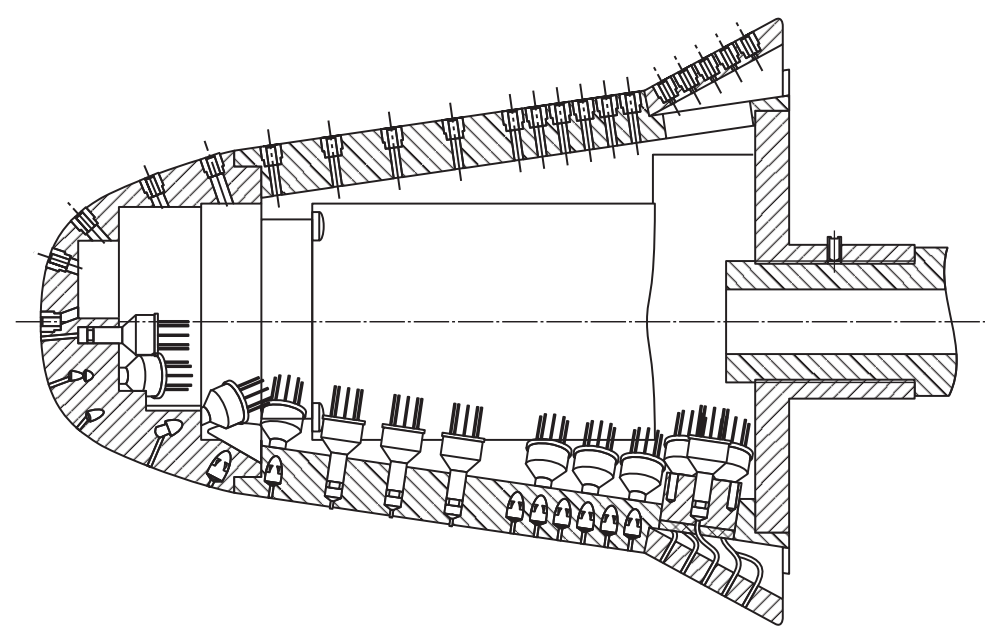

Figure 10 Model for measuring the surface pressure distribution 


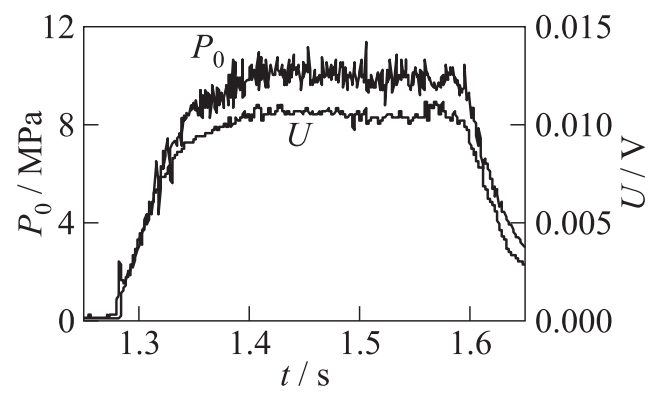

Figure 11 Total pressure in the wind-tunnel settling chamber and the sensor signal vs. time

flow around the model proper and the "zero" sensor indications before and after air exhaustion from the nozzle.

The time evolution of the signals recorded by the pressure sensors placed in the settling chamber and in the first pressure tap is compared in Fig. 11. At the first stage of data processing, time intervals corresponding to the test regime of the wind tunnel were identified. The duration of the test regime was $\sim 150 \mathrm{~ms}$ in the time interval from 1400 to $1550 \mathrm{~ms}$. The pressure sensor produced a uniform signal suitable for subsequent processing. Further processing of the recorded signals was performed by a standard procedure used for AT-303 [10].

The dimensionless pressure distributions over the generatrices of the windward and leeward surfaces in the plane of symmetry of the model are shown in Fig. 12 for different angles of attack $\alpha$. The same figure shows the zoom-in pressure distribution outside the fore body, near the flap, which begins at the coordinate $x=162.5 \mathrm{~mm}$. As it could be expected, an increase in the angle of attack is accompanied by an increase in pressure on the windward side and by a decrease in pressure on the leeward side. The overall level of dimensionless pressure near the stagnation point is $\sim 125$ irrespective of the angle of attack. The most pronounced increase in pressure on the flaps is observed when the angle of attack is increased to $6^{\circ}$. Unfortunately, the small number of pressure taps on the flap provides no clear picture of the flow in this region, in particular, the fact of boundary-layer separation during boundary layer/shock wave interaction.

With the aim of possible refinement of flow parameters, the numerical calculations of an axisymmetric body with the streamwise contour corresponding to the EXPERT model were performed. The calculations were carried out by the FLUENT software system on the basis of the Euler and Navier-Stokes solvers with the $k-\varepsilon$ Re-Normalized Group (RNG) turbulence model. The calculated pressure distributions for a zero angle of attack are plotted in Fig. 13. In particular, the Euler calculations allowed to evaluate the flow parameters in front of 

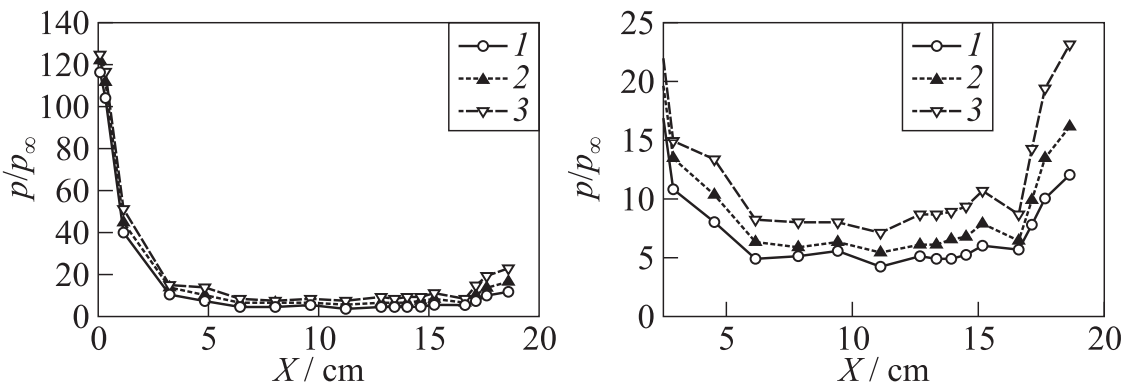

(a)
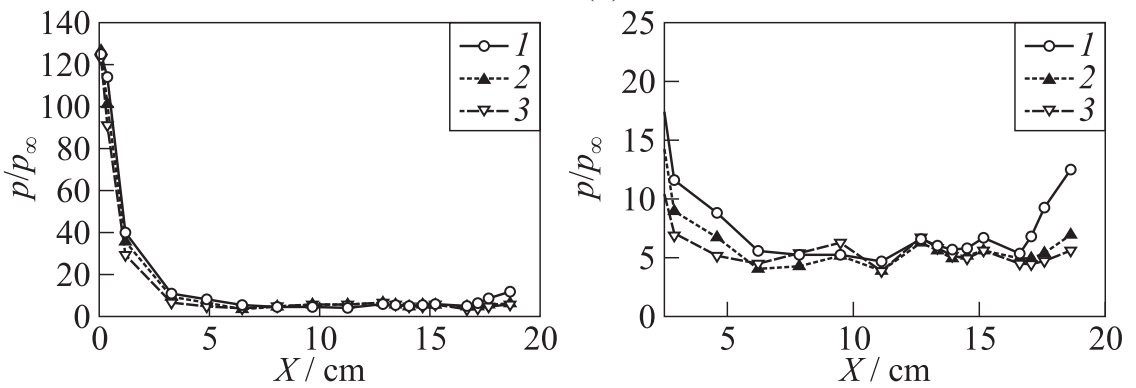

(b)

Figure 12 Distribution of dimensionless pressure over the windward $\left(\gamma=0^{\circ}\right)(a)$ and leeward $\left(\gamma=180^{\circ}\right)(b)$ surfaces of the model: $1-\alpha=0^{\circ} ; 2-3^{\circ}$; and $3-$ $\alpha=6^{\circ}$
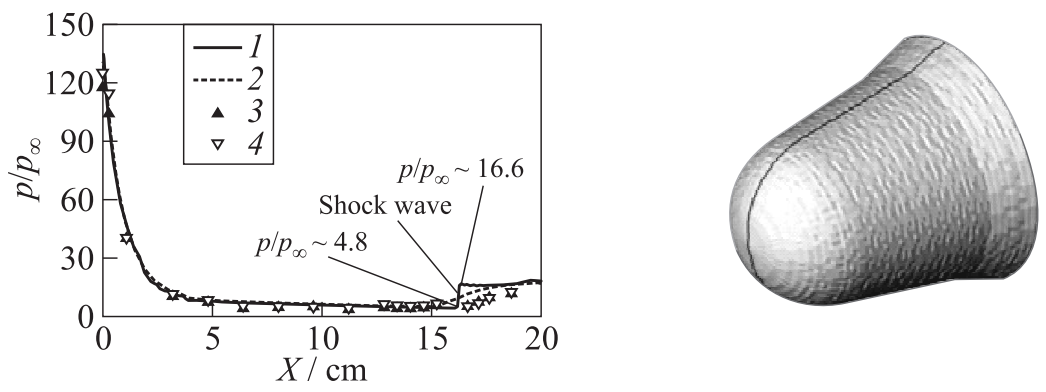

Figure 13 Calculated (curves) and experimental distributions (signs) of pressure at zero angle of attack, $\mathrm{M}=10: 1-$ Euler; $2-k-\varepsilon \mathrm{RNG} ; 3$ - run 2662; and 4 run 2663

the flap and the pressure levels on the flap: the Mach number in front of the flap was $\mathrm{M}_{1}=2.8$, and the pressure difference on the shock wave was $p_{2} / p_{1} \sim 3.5$. A comparison of this pressure level with the simplest estimate of the critical pressure difference for a turbulent boundary layer $\left(\bar{p}_{\mathrm{cr}}=1+0.5 \mathrm{M}_{1}=24\right)$ points 


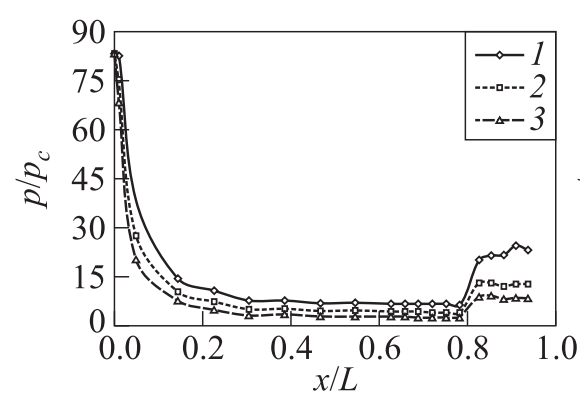

(a)

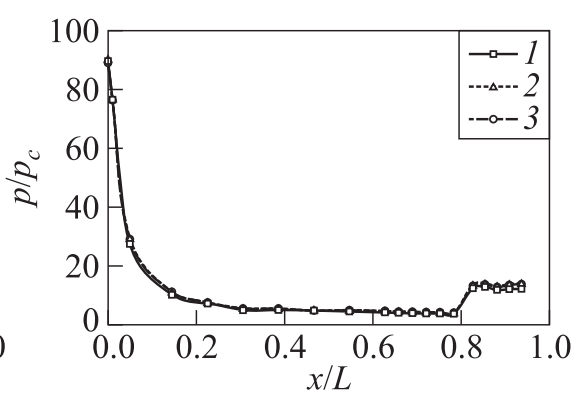

$(b)$

Figure 14 Pressure distribution at $\mathrm{M}=7.8$ at $\alpha=0^{\circ}(a)$ and $\alpha=6^{\circ}(b): 1-$ $\gamma-0^{\circ} ; 2-90^{\circ} ;$ and $3-\gamma=180^{\circ}$

to possible separation of the boundary layer due to its interaction with the shock wave. Subsequent Navier-Stokes calculations confirmed the presence of the separation zone in the flap region. Note also that the pressure distributions outside the separation region almost coincide in viscous and inviscid calculations.

The foregoing results on the pressure distribution are related to the EXPERT 4.2 modifications. The data for EXPERT 4.4 modifications were also obtained at $\mathrm{M}=7.8$ (Fig. 14). Figure $14 a$ shows the dependencies of relative pressures $p / p_{\infty}=f(x / L)$ measured at the zero angle of attack for the rolling angles $\gamma=0^{\circ}$ and $180^{\circ}$. The obtained results indicate the symmetrical flow around the model, absence of flow angularities, and satisfactory degree of the velocity field nonuniformity in the test section. Figure $14 b$ presents similar pressure distributions for the angle of attack $\alpha=6^{\circ}$, measured in different planes of symmetry $\left(\gamma=0^{\circ}\right.$ - windward side, $\gamma=90^{\circ}$ — side surface, and $\gamma=180^{\circ}$ - leeward side). In dependence of the rolling angle, all three pressure distributions are divided into layers and the boundarylayer separation ahead of the flap with consequent reattachment is observed.

The relative pressure distribution on the base section of the model at

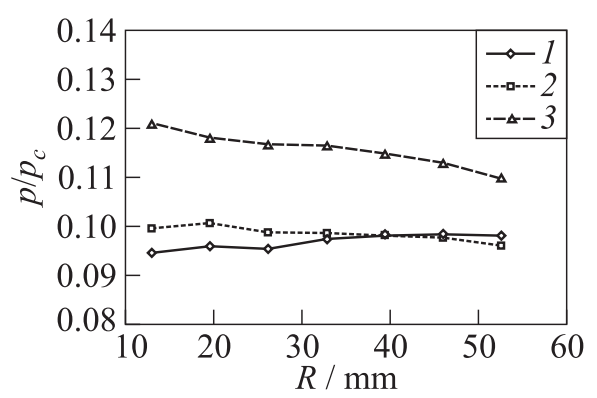

Figure 15 Distribution of base pressure at $\mathrm{M}=7.8: 1-\theta=0^{\circ} ; 2-90^{\circ}$; and $3-$ $\theta=180^{\circ}$

the angle of attack $\alpha=6^{\circ}$ is given in Fig. 15 where $R$ is the distance from the axis of the base section to the measurement point. It is clearly seen that the radial pressure distribution at $\theta=0^{\circ}$ (windward surface) and $\theta=90^{\circ}$ 
(horizontal symmetry plane) lie in the confidential interval of the error. As for the differences of the pressure distribution on the base section (leeward surface region $\theta=180^{\circ}$ ), it should be noted that the values correspond to the measurement points positions in the vertical plane of the model symmetry for the angle of attack $6^{\circ}$. It should also be mentioned that the absolute values of the pressure on the EXPERT-model base surface are very small and reach $\sim 10 \%-12 \%$ from the static pressure in the free stream.

\section{DISTRIBUTION OF HEAT FLUXES ON THE SURFACE}

Heat fluxes were investigated in the wind tunnel AT-303 at $\mathrm{M}=13.93, \alpha=0^{\circ}$, $\mathrm{Re}_{1}=(2.36-2.43) \cdot 10^{7}, T_{0}=(1260-1300) \mathrm{K}, P_{0} \approx 108 \mathrm{MPa}$ for the EXPERT 4.4 model version. The period of the flow working mode existence was about $70 \mathrm{~ms}$. The model was made of Plexiglas (scale 1:8) and had replaceable nose units permitting to form steps in the section of the nose part and body junction. The step was $1 \mathrm{~mm}$ for the model 2 and $2 \mathrm{~mm}$ for the model 3. Thermal loads were measured by two methods: $(i)$ the discrete method involving calorimetric gages of heat fluxes, and (ii) the panoramic infrared (IR) method based on IR thermography (IRT). The calorimetric gages were installed on two model

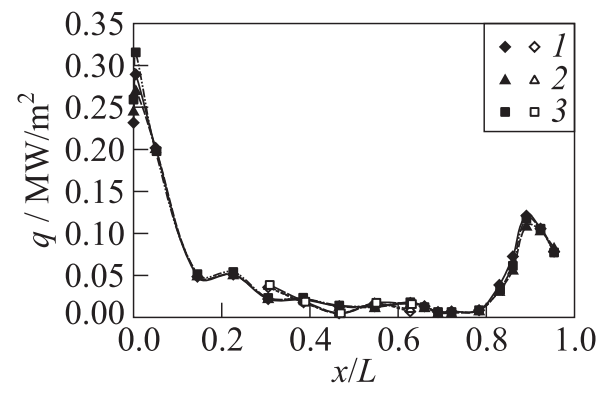

Figure 16 Heat fluxes distribution over the surface of the model without step for different runs: $1-2405 ; 2-2406$; and $3-$ 2408. Empty signs refer to conical nozzle generatrics: in the flap plane of symmetry $\left(\theta=0^{\circ}, 20\right.$ gages $)$ and in the plane between the flaps $\left(\theta=45^{\circ}\right.$, 5 gages). The error of the heat flux measurement did not exceed $10 \%$ from the measured value.

Heat fluxes distribution toward model 1 obtained with the aid of calorimetric gages (Fig. 16) shows that the maximum level of the specific heat flux, which is about $0.3 \mathrm{MW} / \mathrm{m}^{2}$, was reached on the nose part surface, somehow downstream from the stagnation point. Before the flap, the flow separates and then reattaches on the flap surface. The separation region length, found from the minimum level of the heat flux $0.005-0.007 \mathrm{MW} / \mathrm{m}^{2}$, is about $20-25 \mathrm{~mm}$. In the flow reattachment region (approximately on the flap center), the heat flux level has the maximum, and then it decreases in the tail part. The value of the maximum heat flux on the flap surface, according to the results of multifold measurements, varied from 0.12 to 


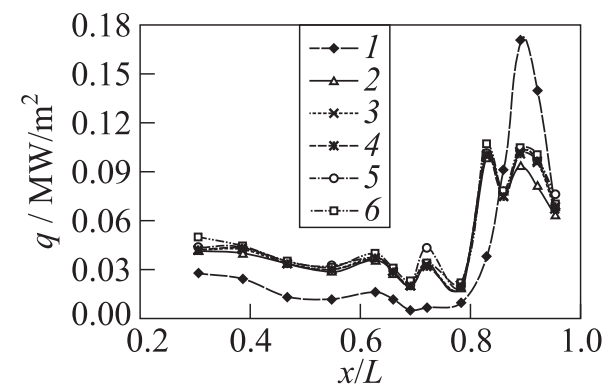

Figure 17 The influence of the surface roughness on heat fluxes to the surface for different runs: $1-2435 ; 2-2436 ; 3-$ $2437 ; 4-2438 ; 5-2439$; and $6-2440$

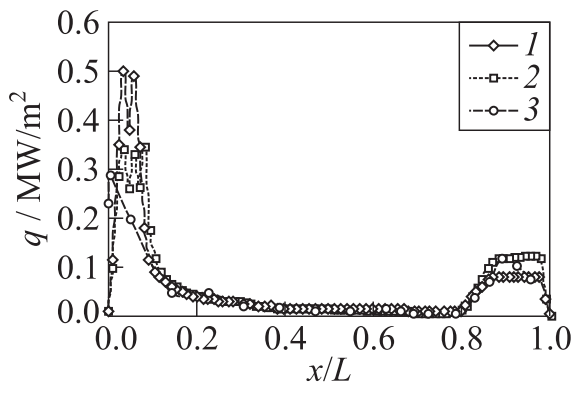

Figure 18 Comparison of heat fluxes distributions obtained by calorimetric $(1-30 \mathrm{~ms}$; and $2-40 \mathrm{~ms})$ and IR gages $(3)$

$0.17 \mathrm{MW} / \mathrm{m}^{2}$, which may result from the nonstationary flow in the reattachment region. On the flat unit of the model surface before the flap, practically constant heat-flux level is kept up to the separation region. At the same time, on the cone surface, the heat-flux level near the nose part is two times higher than on the flat section, and decreases essentially downstream.

To study the influence of the flow turbulization in the boundary layer, model 2 was tested with the increased surface roughness, which was provided by the powder of about $200 \mu \mathrm{m}$ sprayed on the nose part surface. The results of heat fluxes measured by the calorimetric method are shown in Fig. 17 in comparison with the initial version (without turbulization). Increased relative surface roughness in the model nose part resulted in the essential increase of the heat flux levels over the body, decrease of the separation region length before the flap, and thermal load redistribution over the flap surface, the maximum heat flux level being decreased. These results can apparently be caused by the changing character of the flow in the boundary layer, which was, due to the increased roughness of the nose part, transformed from the laminar to turbulent mode.

Figure 18 shows the comparison of the heat fluxes measured by the calorimetric and thermography methods. Good agreement between the data obtained on the model body surface within the working mode time of about $30-40 \mathrm{~ms}$ is observed. Somehow bigger scatter in the data on the nose part can result from the registered overtemperatures against the rated temperature range of the IR camera and essentially changing foreshortening.

Data scattering on the flap is apparently caused by the flow nonstationary in the reattachment region.

The panoramic method of measurements with high spatial resolution permitted (in contrast to the discrete method) to define the size of the separation 


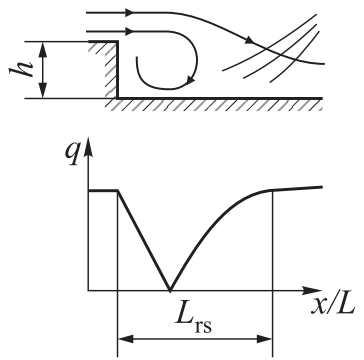

(a)

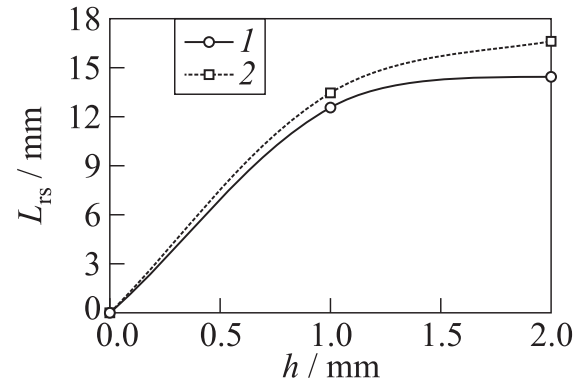

(b)

Figure 19 The influence of the step height on the separation region size: $1-\gamma=0^{\circ}$; and $2-\gamma=45^{\circ}$

regions formed before the flaps and in the area of the nose part and body. In particular, it was shown that the separation region resulted from the interaction between the shock wave generated by the flap and the boundary layer on the body exceeds the side bounds of the flap. The length of the separation region has its maximum in the flap plane of symmetry and decreases when moving off from this plane. The maximum size of the separation region $(21-23 \mathrm{~mm})$ is in good agreement with the calorimetric measurements data. Maximum temperature levels realize near the flap leading edge and side edges.

In the point of nose part and body junction, with the step being present (models 2 and 3 ), the separation region formation downstream is followed by the flow reattachment. The separation region length increases essentially when the step height rises, as is shown in Fig. 19 for the flat $\left(\theta=0^{\circ}\right)$ and conic $\left(\theta=45^{\circ}\right)$ sections of the body surface. The separation region length is somehow bigger on the conic surface $\left(\theta=45^{\circ}\right)$ than on the flat section $\left(\theta=0^{\circ}\right)$.

We do not observe any essential growth of the thermal load level (in respect to model 1) in the region of reattachment of the flow separated because of the step. Thermal load redistributions (in respect to model 1), observed in the area of the studied sizes of the step, do not cause any considerable influence on the separation region forming before the flap.

\section{CONCLUDING REMARKS}

Investigations of the total aerodynamic characteristics of the EXPERT 4.2 model performed in hypersonic wind tunnels T-313 and AT-303 ITAM SB RAS with the countered nozzle within the Mach numbers range $\mathrm{M}=4-14$ show the following: 
- the longitudinal force coefficient weakly depends on the angle of attack within the range of $\alpha$ from $-3^{\circ}$ to $6^{\circ}$ for any free-stream Mach number within the studied range;

- the dependencies of the normal force and pitching moment coefficients on the angle of attack approach to linear ones; and

- the variation of the model rolling angle about the longitudinal axis within the range of $\gamma=0^{\circ}-45^{\circ}$ actually does not influence the aerodynamic characteristics. The observed differences at different $\gamma$ lie within the confidential interval of the error.

The pressure and heat fluxes distributions measured on the surface show the presence of the separation region resulting from the interaction between the shock wave generated by the flap and the boundary layer on the body. Increased roughness of the nose part (a layer of powder of about $20 \mu \mathrm{m}$ ) resulted in considerable increasing of the heat-fluxes level on the body, shortening separation region before the flap and thermal load redistribution over the flap surface, the maximum heat flux level on it being decreased. It can be assumed that the surface roughness has changed the flow character in the boundary layer, namely, has caused the laminar flow transition to the turbulent one.

\section{REFERENCES}

1. Walpot, L., and H. Ottens. 2002. FESART/EXPERT aerodynamic and aerothermodynamic analysis of the RAV and KHEOPS configuration. Technical Report. TOS-MPA/2718/LW. ESTEC.

2. Ottens, H., and L. Walpot. 2003. EXPERT model 4.2, Model description and trajectory analysis. Technical Report. TOS-MPA/2749/HO. ESTEC.

3. Danilkin, V. 2002. Pre-contractual studies of the possibility to launch re-entry vehicles by Volna LV for aerothermodynamic investigations. Technical Report. 000/11340-2002. Makeyev Design Bureau.

4. Kharitonov, A. M., V. I. Zvegintsev, M. D. Brodetsky, I. I. Mazhul, J. M. Muylaert, W. Kordulla, and J. C. Paulat. 2005. Aerodynamic investigation of aerospace vehicles in the new hypersonic wind tunnel AT-303 in ITAM. 4th Symposium (International) on Atmospheric Re-Entry Vehicles and Systems. Arcachon, France.

5. Kharitonov, A. M., N. P. Adamov, M. D. Brodetsky, L. G. Vasenyov, I. I. Mazhul, V. I. Zvegintsev, J. C. Paulat, J. M. Muylaert, and W. Kordulla. 2006. Investigation of aerogasdynamics of re-entry vehicles in the new hypersonic wind tunnel at ITAM. AIAA Paper No. 2006-0499.

6. Kharitonov, A. M., N.P. Adamov, M. D. Brodetsky, L. G. Vasenyov, I. I. Mazhul, and V.I. Zvegintsev. 2006. Investigation of aerogasdynamics of re-entry vehicles in the new hypersonic wind tunnel at ITAM. 6th China-Russia High-Speed Flow Conference Proceedings. Mianyang Sichuan. 
7. Adamov, N.P., M.D. Brodetsky, L. G. Vasenyov, I. I. Mazhul, V.I. Zvegintsev, A. M. Kharitonov, J. C. Paulat, J. M. Muylaert, and W. Kordulla. 2006. Aerodynamics of re-entry vehicles at natural Reynolds numbers. Thermophys. Aeromechanics 13(3):341-51.

8. Adamov, N.P., A.M. Kharitonov, I. I. Mazhul, L. G. Vasenyov, V.I. Zapryagaev, V.I. Zvegintsev, and J. M. Muylaert. 2008. Investigations of aerogasdynamics of re-entry ballistic vehicle expert. 14th Conference (International) of Aerophysical Research Proceedings. Novosibirsk, Russia. CD-ROM. ISBN 978-5-98901-040-0.

9. Shettino, A., R. Votta, P. Roncioni, M. Di Clemente, M. Gerritsma, C. Chiarelli, and D. Ferrarella. 2007. Aerodynamic and aerothermodynamic data base of EXPERT capsule. West-East High-Speed Flow Field Conference Proceedings. Moscow, Russia.

10. Kharitonov, A. M., V.I. Zvegintsev, L. G. Vasenyov, A.D. Kuraeva, D. G. Nalivajchenko, A. V. Novikov, M. A. Paikova, V.F. Chirkashenko, N. V. Shakhmatova, and S. I. Shpak. 2006. Characteristics of the AT-303 hypersonic wind tunnel. Part 1. Velocity fields. Thermophys. Aeromechanics 13(1):1-16. 